\title{
Electrophysiological Dissociation of Picture Versus Word Encoding: The Distinctiveness Heuristic as a Retrieval Orientation
}

\section{Citation}

Budson, Andrew E., Daniel B. J. Droller, Chad S. Dodson, Daniel L. Schacter, Michael D. Rugg, Philip J. Holcomb, and Kirk R. Daffner. 2005. Electrophysiological dissociation of picture versus word encoding: The distinctiveness heuristic as a retrieval orientation. Journal of Cognitive Neuroscience 17(8): 1181-1193.

\section{Published Version}

doi:10.1162/0898929055002517

\section{Permanent link}

http://nrs.harvard.edu/urn-3:HUL.InstRepos:3627126

\section{Terms of Use}

This article was downloaded from Harvard University's DASH repository, and is made available under the terms and conditions applicable to Other Posted Material, as set forth at http:// nrs.harvard.edu/urn-3:HUL.InstRepos:dash.current.terms-of-use\#LAA

\section{Share Your Story}

The Harvard community has made this article openly available.

Please share how this access benefits you. Submit a story.

Accessibility 


\title{
Electrophysiological Dissociation of Picture Versus Word Encoding: The Distinctiveness Heuristic as a Retrieval Orientation
}

\author{
Andrew E. Budson ${ }^{1,2,3}$, Daniel B. J. Droller ${ }^{3}$, Chad S. Dodson ${ }^{4}$, \\ Daniel L. Schacter ${ }^{5}$, Michael D. Rugg', \\ Philip J. Holcomb ${ }^{7}$, and Kirk R. Daffner ${ }^{3,8}$
}

\begin{abstract}
Event-related potentials (ERPs) were used to investigate the neural processes underlying the distinctiveness heuristica response mode in which participants expect to remember vivid details of an experience and make recognition decisions based on this metacognitive expectation. One group of participants studied pictures and auditory words; another group studied visual and auditory words. Studied and novel items were presented at test as words only, with all novel items repeating after varying lags. ERP differences were seen between the word and picture groups for both studied and novel items. For the novel items, ERP differences were largest in frontal and central midline electrodes. In separate analyses,
\end{abstract}

\section{INTRODUCTION}

Although memory is often accurate, memory distortions and false memories frequently occur (Schacter, 1996). False recognition is one type of memory distortion that has been recently studied in the laboratory. False recognition occurs when people incorrectly claim to have previously encountered a novel word or event. During the past several years, there has been growing interest in procedures that reduce the occurrence of false memories (see Schacter \& Wiseman, in press; Dodson, Koutstaal, \& Schacter, 2000, for review). For example, a number of experiments have observed reduced false recognition of novel items that are semantically related to previously studied items when the study and test trials are repeated multiple times (Budson, Daffner, Desikan, \& Schacter, 2000; Kensinger \& Schacter, 1999; Schacter, Verfaellie, Anes, \& Racine, 1998; McDermott, 1996).

\footnotetext{
${ }^{1}$ Edith Nourse Rogers Memorial Veterans Hospital, Bedford, MA, ${ }^{2}$ Boston University, ${ }^{3}$ Brigham and Women's Hospital, Boston, MA, ${ }^{4}$ University of Virginia, ${ }^{5}$ Harvard University, ${ }^{6}$ University of California, Irvine, ${ }^{7}$ Tufts University, Medford, MA, ${ }^{8}$ Harvard Medical School
}

the picture group showed the greatest ERP differences between item types in a parietally based component from 550 to $1000 \mathrm{msec}$, whereas the word group showed the greatest differences in a frontally based component from 1000 to $2000 \mathrm{msec}$. The authors suggest that the distinctiveness heuristic is a retrieval orientation that facilitates reliance upon recollection to differentiate between item types. Although the picture group can use this heuristic and its retrieval orientation on the basis of recollection, the word group must engage additional postretrieval processes to distinguish between item types, reflecting the use of a different retrieval orientation.

Israel and Schacter (1997) investigated another method to reduce false recognition. They tested the idea that if false recognition of semantically related words depends upon participants' reliance upon the common semantic features or gist of the study list, then it should be possible to reduce false recognition following study conditions that promote encoding of distinctive information about particular items. Israel and Schacter presented one group of young adults with lists of semantic associates in which each word was presented auditorily and was also accompanied by a corresponding picture. A second group heard the same words auditorily, but instead of an accompanying picture, they saw the visual presentation of the word. Israel and Schacter found that pictorial encoding yielded lower levels of false recognition of both semantically related and unrelated lures than did word encoding alone.

In a follow-up study, Schacter, Israel, and Racine (1999) found that participants showed a more conservative response bias after picture encoding than after word encoding. They suggested that this more conservative response bias observed after picture encoding may depend on a general shift in responding based on participants' metamemorial assessments of the kinds of information they feel they should remember (Strack \& 
Bless, 1994). Because they had encountered pictures with each of the presented words, participants in the picture encoding condition used a general rule of thumb, whereby they demanded access to detailed pictorial information in order to support a positive recognition decision; failure to gain access to such distinctive information when tested with related lures would tend to result in a negative recognition decision. Importantly, Schacter, Israel, et al. (1999) argued that suppression, on the basis of metamemorial assessments, can function without access to specific information regarding the particular items studied. They hypothesized that the suppression of false recognition observed in the picture encoding group thus relied on a general expectation that a test item should elicit a vivid perceptual recollection if, indeed, it had been presented previously. Participants in the word encoding group, in contrast, would not expect to retrieve distinctive representations of previously studied items and are thus much less likely to demand access to detailed recollections. Schacter, Israel, et al. referred to the hypothesized rule of thumb used by the picture encoding group as a "distinctiveness heuristic" (cf., Johnson, Hashtroudi, \& Lindsay, 1993; Chaiken, Lieberman, \& Eagly, 1989; Kahneman, Slovic, \& Tversky, 1982).

Additional studies have explored the distinctiveness heuristic using other false recognition paradigms. Dodson and Schacter (2002a) used the repetition-lag paradigm of Underwood and Freund (1970), later modified by Jennings and Jacoby (1997). In the study of Dodson and Schacter (2002a), participants first studied a list of unrelated words. Although all participants heard the words auditorily, some of the participants saw the accompanying visual word, whereas others saw a picture representing the word. At test, both groups were shown studied and new words. Importantly, all of the new words repeated after a varying lag of intervening words. Participants were instructed to respond "old" to studied words, and were specifically warned to avoid responding "old" to the repeated new words. As in the previous studies (Schacter, Israel, et al., 1999; Israel \& Schacter, 1997), Dodson and Schacter (2002a) found that those who studied pictures showed lower rates of false recognition than those who studied only words.

Whereas much is known about the cognitive processes that are involved in using the distinctiveness heuristic, Schacter and Wiseman (in press) note that nothing is known about the corresponding brain processes. Recent reports suggest that studying pictures can change the "retrievalorientation" of the participants, compared to studying words (Herron \& Rugg, 2003; Robb \& Rugg, 2002). Rugg and Wilding (2000) describe retrieval orientation as that which determines the particular form of the processing that is applied to a cue at retrieval. They also postulated that the neural correlates of the retrieval orientation could be observed in a paradigm which used identical retrieval cues to probe memory for different kinds of information-if such cues were unrelated to the studied items (i.e., novel items in a recognition memory test). Robb and Rugg (2002) first suggested that the distinctiveness heuristic could be explained as the adoption of a particular retrieval orientation.

In the present study, we set out to examine the neural correlate of the distinctiveness heuristic using eventrelated potentials (ERPs). We hypothesized that if the distinctiveness heuristic changed the retrieval orientation of the participants who studied pictures in comparison to those who studied words, we should see ERP differences between the two groups for the novel words at test. Alternatively, if studying pictures was unrelated to a change in retrieval orientation and instead only increased the participants' ability to remember the specific details of a prior encounter with a particular item (item-specific recollection) compared with those who studied words, then we would expect to see ERP differences between the two groups only for studied items, and not for novel items.

We used a repetition-lag paradigm very similar to that of Dodson and Schacter (2002b) to distinguish between these two possibilities. During the study session participants heard 100 words presented auditorily and performed a syllable counting task. Half of the participants also saw the word presented visually on the screen; the other half saw a corresponding Snodgrass and Vanderwart (1980) picture. At test, all participants heard auditory words accompanied by the visual word. In addition to the 100 studied words and 100 novel words, 50 of the novel words were repeated after two intervening words (lag 2) and the other 50 novel words were repeated after 48 intervening words (lag 48). As argued by Schacter, Israel, et al. (1999), we did not believe that an increase in item-specific recollection alone could explain the results that have been attributed to the distinctiveness heuristic (Budson, Dodson, Daffner, \& Schacter, 2005; Budson, Dodson, Vatner, et al., 2005; Budson, Sitarski, Daffner, \& Schacter, 2002; Dodson \& Schacter, 2002a, 2002b; Israel \& Schacter, 1997). We therefore predicted that we would find ERP differences between the word and picture groups for the novel items. This finding would suggest that the distinctiveness heuristic is a type of retrieval orientation which participants may engage after studying pictures.

\section{RESULTS \\ Behavioral Results}

An analysis of variance (ANOVA) on the proportion of old responses with group (word, picture) as a betweensubjects variable and item type (study, novel, lag 2, lag $48)$ as a within-subjects variable yielded an effect of item type $[F(3,66)=130.03$, MSE $=0.009, p<.0005]$ and a Group $\times$ Item type interaction $[F(3,66)=7.22, M S E=$ $0.009, p<.0005]$ (Table 1$)$. The effect of group did not 
Table 1. Proportion "Old" Responses to Study, Novel, and Repeated Lag Items by Word and Picture Encoding Condition

\begin{tabular}{lcccccc}
\hline Encoding Condition & Study & Novel & $d^{\prime}$ & $C$ & Lag 2 & Lag 48 \\
\hline Word, mean $(S D)$ & $0.60(0.05)$ & $0.24(0.03)$ & 1.04 & 0.41 & $0.15(0.04)$ & $0.37(0.05)$ \\
Picture, mean (SD) & $0.61(0.06)$ & $0.12(0.03)$ & 1.64 & 0.75 & $0.11(0.04)$ & $0.15(0.04)$ \\
\hline
\end{tabular}

reach significance $[F(1,22)=2.89, M S E=0.066, p=$ .103]. Post hoc one-way ANOVAs show that the interaction is due to differences between the groups for novel $[F(1,22)=6.45, M S E=0.013, p=.019]$ and lag 48 $[F(1,22)=11.95, M S E=0.024, p=.002]$ items, but not for study or lag 2 items $[F s(1,22)<1])$ (Table 1). Thus, the behavioral results show that studying pictures allowed a reduction in false alarms to novel and lag 48 items, consistent with the use of the distinctiveness heuristic. These results are consistent with the work of Dodson and Schacter (2002a, 2002b).

We also performed signal detection analyses of the hit and false alarm rates to novel and lag items, using $d^{\prime}$ as a measure of sensitivity and $C$ as a measure of response bias, as described by Snodgrass and Corwin (1988). A one-way ANOVA for $d^{\prime}$ revealed significant differences between the groups, reflecting the greater ability of the picture group to distinguish between study and novel items $[F(1,22)=8.09, M S E=0.263, p=.009]$ (Table 1$)$. There was a trend towards a difference between the groups in the bias measure $C[F(1,22)=3.21, M S E=$ $0.213, p=.087$ ] which, as suggested by the significant difference in their false alarms to novel items, is attributable to the picture group being somewhat less likely to respond "yes" compared with the word group.

\section{ERP Overall Analyses}

Grand-average ERP waveforms for all electrodes are shown in Figure 1 for correct rejection of novel items for the word and picture groups. Mean amplitudes were analyzed for four intervals (150-300, 300-550, 550-1000,

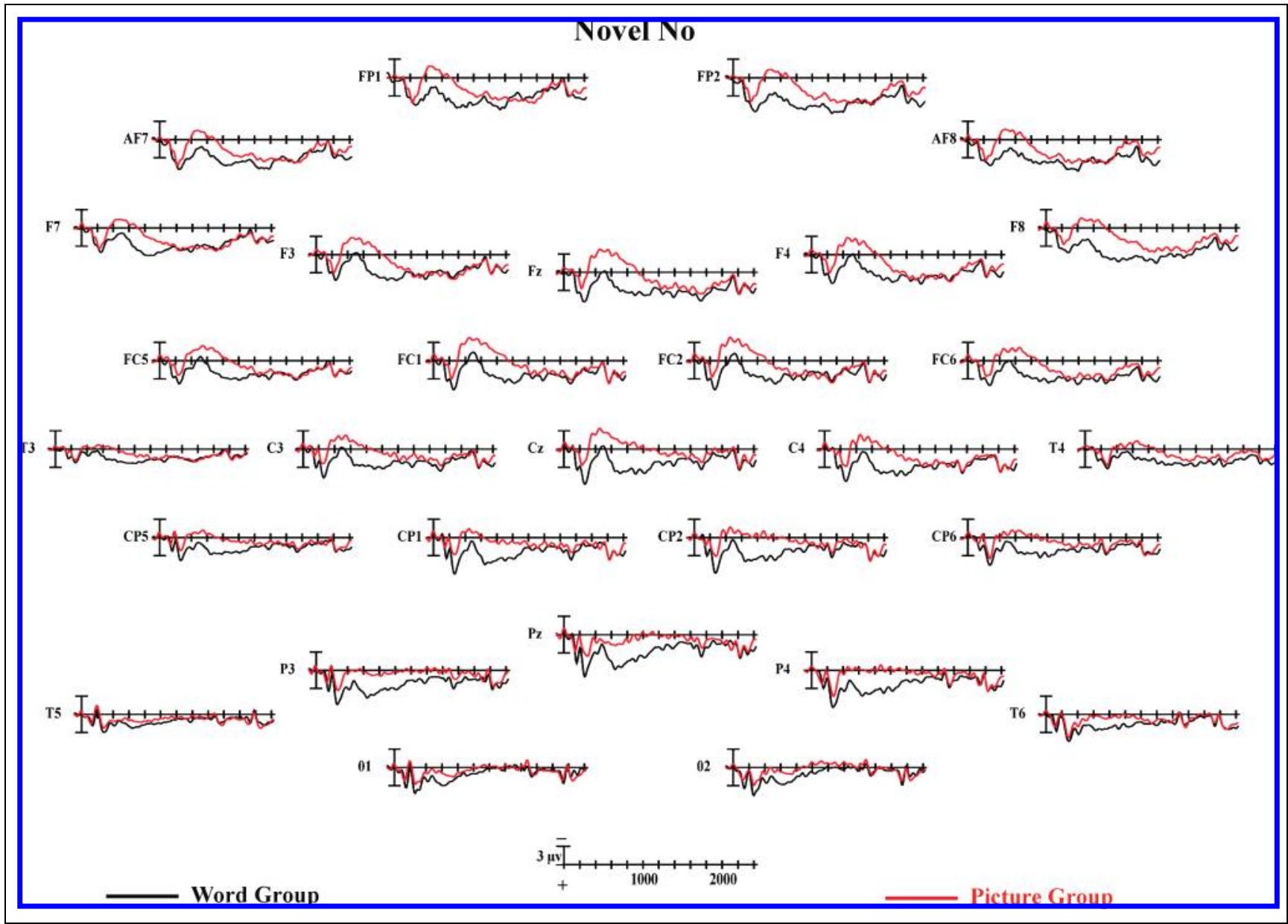

Figure 1. Grand-average ERP plots for all electrodes for correct rejection of novel items by group. Positive is plotted down, tics are every $200 \mathrm{msec}$. 
1000-2000 msec) based upon visual inspection of the waves and previous ERP recognition memory studies which have identified a P200 component, an N400-like component, a parietal component (also known as the late positive component or LPC), and a late frontal component (e.g., Curran, Schacter, Johnson, \& Spinks, 2001). Midline and lateral sites were analyzed separately and together with the lateral sites grouped in coronal rows of three or four electrodes as described in the Methods. These preliminary analyses revealed that the general pattern of results showed an anterior to posterior gradient, no difference between hemispheres, and little difference between midline and lateral sites with the midline sites showing the largest effects. The remainder of the analyses was therefore performed with the midline electrodes.

For the midline sites, we initially performed an overall ANOVA with group (word, picture) as a between-subjects variable and item type (correct responses to study, novel, lag 2, lag 48) and electrode (Fz, Cz, Pz) as withinsubjects variables. For the first interval, there was a trend toward an effect of group $[F(1,22)=3.58, M S E=75.32$, $p=.072]$. For the second interval, there was a main effect of item type $[F(3,66)=12.01, M S E=9.97$, $p<.0005]$ and an Item type $\times$ Electrode interaction $[F(6,132)=9.59, M S E=1.62, p<.0005]$. For the third interval, there was a main effect of item type $[F(3,66)=$ $10.05, M S E=10.78, p<.0005]$ and interactions of Item type $\times$ Group $[F(3,66)=6.05, M S E=10.78, p=.002]$ and Item type $\times$ Electrode $[F(6,132)=5.23, M S E=$ $1.28, p=.001]$; there was a weak trend toward the effect of group $[F(1,22)=3.15, M S E=95.34, p=.090]$. For the fourth interval, there was an effect of item type $[F(3,66)=10.69, M S E=7.67, p<.0005]$ and no interactions. There were also effects of electrode (or trends toward an effect) for all four intervals [first: $F(2,44)=3.06, M S E=4.52, p=.079$; second: $F(2,44)=$ 46.86, $M S E=8.69, p<.0005$; third: $F(2,44)=21.06$, $M S E=10.31, p<.0005 ;$ fourth: $F(2,44)=24.95, M S E=$ $5.41, p<.0005]$. In the first interval, the trend was attributable to the tendency for Pz to be more positive than Fz $[F(1,22)=3.57, M S E=4.99, p=.072]$. The effect of electrode is present in the second and third intervals because $\mathrm{Pz}$ was more positive than $\mathrm{Fz}$ [second: $F(1,22)=57.95, M S E=10.32, p<.0005$; third: $F(1,22)=$ $28.05, M S E=11.21, p<.0005]$, whereas in the fourth interval the effect is present because Fz was more positive than Pz $[F(1,22)=29.58, M S E=6.20, p<.0005]$. Old-new effects are of interest and were sought for each interval. Only the third interval showed a weak trend toward an Item type $\times$ Electrode interaction $[F(2,44)=$ $2.64, M S E=0.784, p=.095]$, which was attributable to a significant old-new effect at Pz $[F(1,22)=4.40, M S E=$ $2.81, p=.048]$ due to the brain activity for "yes" responses to study items being more positive than that for "no" responses to novel items. Although a number of additional post hoc tests could be performed to follow up on these main effects and interactions, we will limit our analyses to those that will shed light on the questions raised in the Introduction.

\section{ERP Analyses of Separate Item Types by Group}

\section{Study Items}

A series of ANOVAs with group (word, picture) as a between-subjects variable and electrode $(\mathrm{Fz}, \mathrm{Cz}, \mathrm{Pz})$ as a within-subjects variable for "yes" responses to study items revealed an effect of group for the third interval $[F(1,22)=7.96, M S E=29.36, p=.010]$ but not for the second $[F(1,22)=2.59, M S E=38.94, p=.122]$ or fourth $[F(1,22)=2.04, M S E=11.58, p=.168]$ intervals. The analysis for the first interval revealed a nearsignificant effect of group $[F(1,22)=3.84, M S E=$ $22.59, p=.063]$ and a significant Group $\times$ Electrode interaction $[F(2,44)=8.28, M S E=0.62, p=.002]$ attributable to effects of group at $\mathrm{Cz}[F(1,22)=5.33, M S E=$ 7.69, $p=.031]$ and $\mathrm{Pz}[F(1,22)=6.28, M S E=7.23$, $p=.020]$. These effects of group are present because in the first and third intervals the study-yes responses of the word group evoke more positive brain responses than those of the picture group (Figure 2). There were no other interactions between group and electrode.

\section{Novel Items}

Analogous ANOVAs for "no" responses to novel items also revealed an effect of group for the first $[F(1,22)=$ 4.58, MSE $=17.22, p=.044]$ and third $[F(1,22)=6.34$, $M S E=36.26, p=.020]$, but not second $[F(1,22)=2.71$, $M S E=42.90, p=.114]$ or fourth $[F(1,22)=1.01, M S E=$ $7.83, p=.324]$ intervals. There was also a near-significant Group $\times$ Electrode interaction in the second interval $[F(2,44)=3.22, M S E=2.27, p=.061]$, which was not present in the first, third $[F s(2,44)<1]$, or fourth $[F(2,44)=$ $1.17, M S E=1.66, p=.308]$ intervals. Post hoc tests exploring this near-significant Group $\times$ Electrode interaction in the second interval and the effect of group in the third interval reveal that the brain responses of the word group were more positive than those of the picture group at $\mathrm{Fz}[F(1,22)=4.81, M S E=30.30, p=.039]$ and $\mathrm{Cz}[F(1,22)=5.42, M S E=26.21, p=.029]$ but not at $\mathrm{Pz}[F(1,22)=3.05, M S E=19.86, p=.095]$ (Figure 3). Thus, the brain responses of the word group were more positive when rejecting novel items than those of the picture group (Figures 1, 2, and 3), consistent with previous studies (Herron \& Rugg, 2003; Robb \& Rugg, 2002).

\section{Lag Items}

In contrast to the results of the study and novel items, the ANOVAs for the "no" responses to lag 2 items 


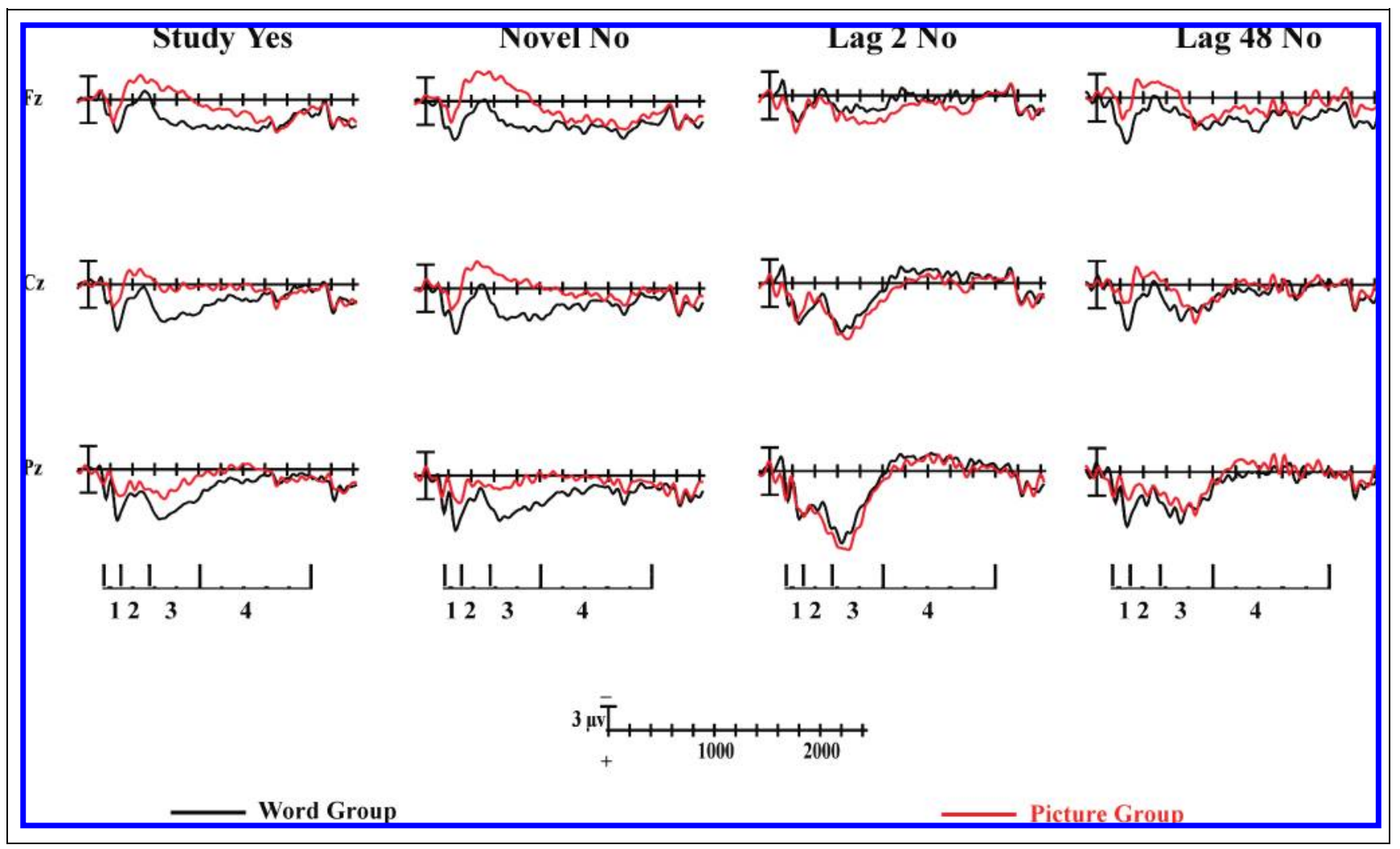

Figure 2. Grand-average ERP plots for midline electrodes for each item type (correct responses to study, novel, lag 2 , and lag 48 items) by group (word vs. picture encoding). Positive is plotted down, tics are every $200 \mathrm{msec}$. The bar indicates the intervals of interest $(1=150-300 \mathrm{msec}$; $2=300-550 \mathrm{msec} ; 3=550-1000 \mathrm{msec} ; 4=1000-2000 \mathrm{msec}$ ).

showed no effects of group $[F \mathrm{~s}(1,22)<1]$ and no interactions between group and electrode. The ANOVA for the "no" responses to lag 48 items showed an effect of group for the first interval $[F(1,22)=4.61, M S E=$ 19.94, $p=.043]$, but not the second $[F(1,22)=1.42$, $M S E=47.46, p=.246]$, third, or fourth $\left[F_{\mathrm{S}}(1,22)<1\right]$; there were no interactions between group and electrode. The effect of group in the first interval is present because the brain activity associated with correct rejection of the lag 48 items was more positive for the word group than the picture group.
In summary, these ERP analyses of the separate item types demonstrate significant differences in brain activity between the word and picture groups for the novel items, supporting our hypothesis that the picture group's use of the distinctiveness heuristic changed their retrieval orientation relative to that of the word group. Although we have, therefore, answered the primary question of this study, an additional question remains unanswered. How does the neural difference in retrieval orientation between the groups explain the behavioral difference in their performance? As discussed

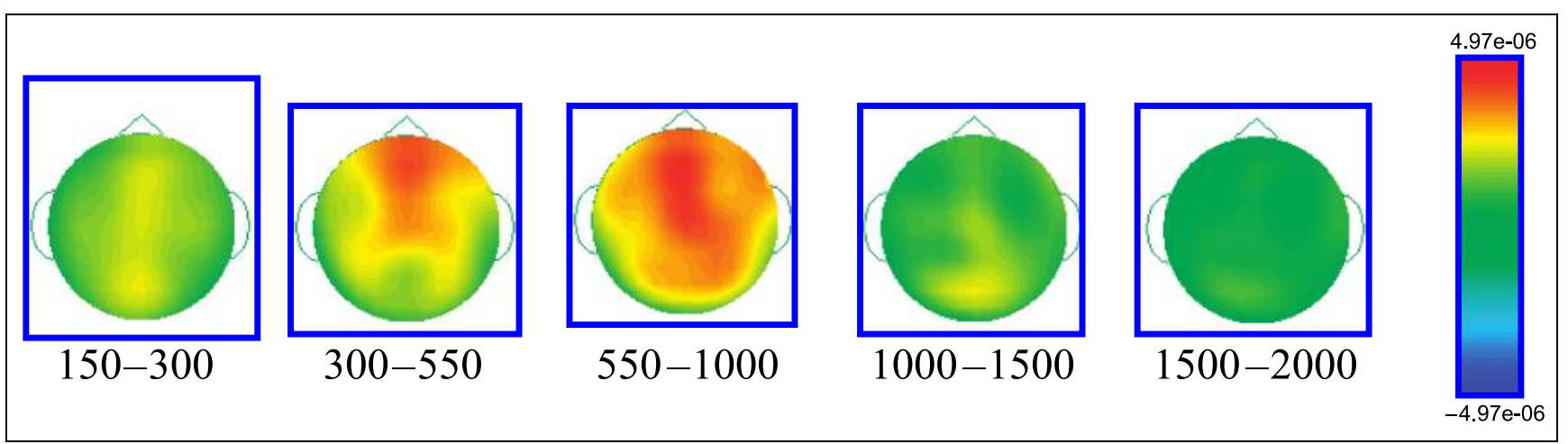

Figure 3. Topographic distributions of ERP differences between word and picture groups for correct rejection of novel items by interval. 
by Herron and Rugg (2003), we suspected that the answer might be related to electrophysiological differences between item types being present in different intervals for the word and picture groups.

\section{ERP Analyses of the Separate Groups by Item Types}

In order to ascertain which interval or intervals were related to the ability of each group (word or picture) to distinguish between the different item types, we next examined the word and picture groups separately for each interval across all four item types. Effect sizes $\left(\eta^{2}\right)$ are also reported in these analyses to obtain a measure of the relative importance of the different processing used by the groups to separate the item types as indexed during different temporal intervals.

\section{Word Group}

An ANOVA with item type (correct responses to study, novel, lag 2, lag 48), and electrode (Fz, Cz, Pz) as withinsubject variables for the word group in the first interval yielded no effect of item type and no interaction (Table 2 and Figure 4). The analysis of the second interval revealed an effect of item type and an Item type $\times$ Electrode interaction. In the third interval, there was no effect of item type (Figure 5); there was a trend toward the interaction. The fourth interval revealed an effect of item type and no interaction.

\section{Picture Group}

An analogous ANOVA for the picture group in the first interval found no effect of item type and no interaction (Table 2 and Figure 4). The analysis of the second interval revealed an effect of item type and an Item type $\times$ Electrode interaction. In contrast to that of the word group, the analysis of the third interval for the picture group revealed a robust effect of item type (Figure 5) in addition to an Item type $\times$ Electrode interaction. For the picture group, the analysis of the fourth interval showed an effect of item type and no interaction.

In brief, these analyses show that although distinct brain activity was present for the different item types in both the word and picture groups for the second and fourth intervals, only the picture group showed differences in the magnitude of the electrophysiological responses for the different item types in the third interval (Table 2 and Figures 4 and 5). Further, the effect sizes show that for the word group the largest difference in brain activity between item types was present in the fourth interval, whereas for the picture group the largest difference in brain activity between item types was present in the third interval. The substantial difference between the groups' ability to distinguish the item types in the third interval is supported by
Table 2. ANOVA Results of Within-Group ERP Analyses for Each Latency Interval

\begin{tabular}{lcccc}
\hline Group, Effect, Interval & $F(d f)$ & MSE & $p$ & $\eta^{2}$ \\
\hline Word & & & & \\
Effect of item type & $(3,33)$ & & & \\
$\quad$ First interval & $<1$ & & $>.300$ & $<.1$ \\
Second interval & 3.52 & 9.85 & .041 & .242 \\
Third interval & 1.18 & 11.58 & .328 & .097 \\
Fourth interval & 7.55 & 7.47 & .002 & .407 \\
Item type $\times$ Electrode & $(6,66)$ & & & \\
First interval & 1.32 & 2.51 & .287 & .107 \\
Second interval & 5.10 & 2.68 & .016 & .317 \\
Third interval & 2.42 & 1.75 & .083 & .180 \\
Fourth interval & $<0.1$ & & & $<.01$
\end{tabular}

Picture

\begin{tabular}{crrrr} 
Effect of item type & $(3,33)$ & & & \\
First interval & 1.45 & 5.69 & .252 & .116 \\
Second interval & 8.78 & 11.37 & $<.0005$ & .444 \\
Third interval & 14.03 & 11.53 & $<.0005$ & .561 \\
Fourth interval & 3.79 & 9.04 & .030 & .256 \\
Item type $\times$ Electrode & $(6,66)$ & & & \\
First interval & 2.06 & 0.773 & .134 & .158 \\
Second interval & 6.45 & 1.21 & .002 & .370 \\
Third interval & 4.61 & 1.21 & .006 & .295 \\
Fourth interval & 1.27 & 1.58 & .286 & .103 \\
\hline
\end{tabular}

a 2 (group: picture vs. word) $\times 4$ (item type: correct responses to study, novel, lag 2 , lag 48 ) $\times 3$ (electrode: $\mathrm{Fz}, \mathrm{Cz}, \mathrm{Pz})$ ANOVA which yielded a Group $\times$ Item type interaction $[F(3,66)=6.05, M S E=10.78, p=.002]$. [The analogous ANOVAs for the first, second, and fourth intervals did not show such an interaction, Fs $(3,66)<$ 1.2.]

\section{DISCUSSION}

Our behavioral data revealed that participants who studied pictures along with auditory words showed lower rates of false recognition compared with those who studied visual and auditory words, consistent with previous studies (Budson, Dodson, Daffner, et al., 2005; Budson, Dodson, Vatner, et al., 2005; Dodson \& Schacter, 2002a, 2002b; Schacter, Israel, et al., 1999). Schacter and colleagues have argued that this reduction of false recognition is attributable to the use of a distinctiveness heuristic. To evaluate how the distinc- 
Figure 4. Grand-average ERP plots for midline electrodes for each group (word vs. picture encoding) by item type (correct responses to study, novel, lag 2, and lag 48 items). Positive is plotted down, tics are every $200 \mathrm{msec}$. The bar indicates the intervals of interest $(1=150-300 \mathrm{msec}$; $2=300-550 \mathrm{msec}$;

$3=550-1000 \mathrm{msec}$ $4=1000-2000 \mathrm{msec})$.

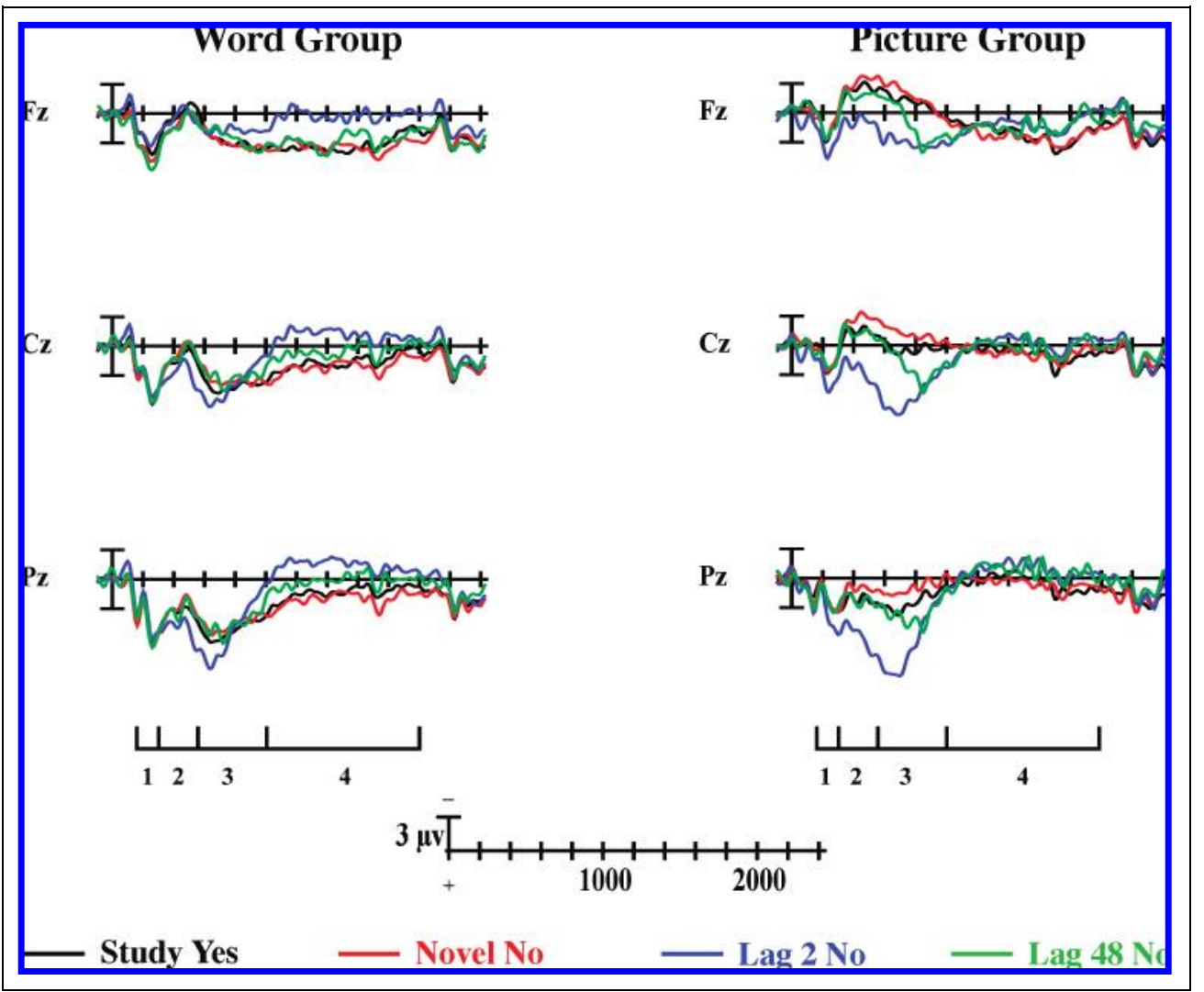

tiveness heuristic alters the way the brain processes items, we recorded ERPs at test. We suspected that the distinctiveness heuristic could be understood as a particular retrieval orientation in which participants may engage at test following picture encoding at study, consistent with previous work (Herron \& Rugg, 2003; Robb \& Rugg, 2002). Following Rugg and Wilding (2000), we hypothesized that if the picture group used a different retrieval orientation than the word group, then the neural correlates of these differences should be manifest even for the unstudied, novel items. If, on the other hand, the differences between picture and word

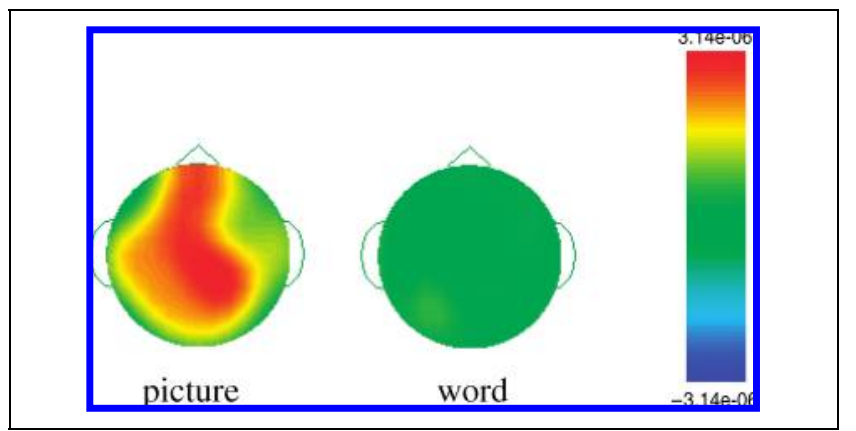

Figure 5. Topographic distributions of ERP differences between correct responses to lag 48 and novel items for the third interval (550-1000 msec) by group (word vs. picture encoding). encoding are solely due to item-specific recollection (rather than a different retrieval orientation), then any ERP differences observed should be present only in actually studied items, and not in novel items.

We found that ERP differences were present between those who studied pictures versus those who studied words for both study and novel items (Figures 1, 2, and 3), consistent with the idea first suggested by Robb and Rugg (2002) that the distinctiveness heuristic may be understood as a type of retrieval orientation which participants may engage in at test following picture encoding at study. ${ }^{1}$ To understand the way in which this change in retrieval orientation altered how the groups distinguished between different item types, we next analyzed the effect of item type for the word and picture groups separately for each time interval. These results showed that the largest effect of item type was present in the third interval for the picture group $\left(\eta^{2}=\right.$ .561) and in the fourth interval for the word group $\left(\eta^{2}=\right.$ .407) (Table 2, Figures 4 and 5). Highlighting these differences between the groups, effects of item type were smallest for the picture group in the fourth interval, and lacking altogether for the word group in the third interval (Table 2).

Linking our intervals to previously described ERP components may help us to understand the differences in the retrieval orientation used by the picture and word groups. We divided our ERP waves into intervals based 
upon previous ERP studies of recognition memory that have identified an early P200 component that is both repetition and modality sensitive and may be related to implicit perceptual processing (Henson, Rylands, Ross, Vuilleumeir, \& Rugg, 2004; Rugg \& Allan, 2000), a frontocentral N400-like component associated with "knowing" or familiarity (Curran \& Cleary, 2003; Curran et al., 2001; Curran, 2000; Duzel, Yonelinas, Mangun, Heinze, \& Tulving, 1997; but see also Yovel \& Paller, 2004, for another view of the N400), a parietal component believed to reflect brain processes related to recollection (Curran \& Cleary, 2003; Goldmann et al., 2003; Curran et al., 2001; Nessler, Mecklinger, \& Penney, 2001; Curran, 2000; Duzel et al., 1997; Johnson, Nolde, et al., 1997), and a late, frontally based component thought to reflect postretrieval processing when the contents of memory must be evaluated for particular features, source information, and other details (Curran \& Cleary, 2003; Goldmann et al., 2003; Curran et al., 2001; Nessler et al., 2001; Ranaganath \& Paller, 2000; Rugg \& Allan, 2000; Allan, Wilding, \& Rugg, 1998; Wilding \& Rugg, 1996). Given our results and these studies, we think it likely that our first interval is measuring this P200 component that may be related to implicit perceptual processing, our second interval (showing the most negativity in the frontal electrode $\mathrm{Fz}$ ) is measuring this N400-like component, our third interval (which shows the most positivity in the parietal electrode $\mathrm{Pz}$ ) is measuring this same parietal effect, and our fourth interval (which shows the most positivity in the frontal electrode $\mathrm{Fz}$ ) is measuring the late frontal effect.

Having placed our ERP intervals within a broader context, we propose the following explanation. Participants in the picture group adopted the metacognitive strategy of the distinctiveness heuristic at test, using the rule of thumb, "if I had seen this item at study, I would remember the picture." This metacognitive strategy led to a retrieval orientation in which these participants in the picture group were able to rely upon recollection (reflected by the parietal component) to determine whether a test item had been studied. Participants in the word group, on the other hand, were less able to rely upon recollection to determine whether an item had been studied; these participants needed to engage in additional postretrieval processing (reflected by the late frontal component) to determine if an item had appeared on the study list rather than previously on the test list. ${ }^{2}$ Close inspection of Figure 4 supports this interpretation. For the picture group, there are clear differences at $\mathrm{Pz}$ between all item types in the third interval (550-1000 msec), and very little, if any, differences between item types in the fourth interval (1000-2000 msec). By contrast, in the word group the only difference between item types present at $\mathrm{Pz}$ in the third interval is between lag 2 and the others; there are no observable differences here between study, novel, and lag 48 items. There are, however, observable differ- ences for the word group between item types in the fourth interval.

Thus, the present study suggests that the distinctiveness heuristic is a retrieval orientation that facilitates or encourages reliance upon recollection to differentiate between the different item types. A different retrieval orientation is used by the word group in this paradigm. Having no such heuristic to use, recollection alone fails to distinguish the different test items. Participants in the word group must instead engage additional postretrieval processes, such as source monitoring, reflected by the late frontal ERP component.

Although the ERP differences between groups for novel items indicates that the picture group used a different retrieval orientation than the word group, it does not imply that recollection of studied items was equal between the two groups. After all, the distinctiveness heuristic is based upon subjects' metamemorial belief that they will remember pictures better than words, and of course, this belief is correct: All other factors being equal, pictures are better recollected than words. The picture group clearly took advantage of this richer recollection to distinguish between items, as reflected by the parietal component (discussed above). As expected, the distinctiveness heuristic allowed the picture group to reject more unstudied items than the word group, reflecting a more conservative response bias in the picture group. Differences in familiarity (reflected by the N400) were also present for item types in both the word and picture groups, and may additionally contribute to the ERP differences observed between groups. It is likely that compared to studying words, studying pictures improves recollection of the study items and changes the subjects' retrieval orientation, and that these differences in recollection and retrieval orientation in turn lead to changes in the subjects' response bias. The present study cannot determine the exact contributions of retrieval orientation, recollection, familiarity, and response criteria to the ERP differences observed between the word and picture groups. Future ERP studies of the distinctiveness heuristic using paradigms that attempt to equate recollection, familiarity, and bias between the word and picture groups (such as that by Gallo, Weiss, \& Schacter, 2004) will be helpful in teasing apart these issues.

The findings of the first interval deserve discussion. There were reliable differences between the word and picture groups in this interval for novel (along with study and lag 48) items (Figures 1 and 2). By contrast, however, there were no differences between item types in the within-group analyses for the separate word and picture groups in this interval (Figure 4). Together, these findings suggest that whereas the retrieval orientation of the groups differed in this early period of brain activity, activity in this interval did not aid subjects in their discrimination between item types. These findings 
also have implications for understanding this interval. If our first interval reflects implicit perceptual processing, then our results suggest that top-down modulation of this perceptual processing may occur, and may differ depending upon the retrieval orientation of the subject.

The ERP responses to lag 2 items are also noteworthy. As mentioned above, even the word group shows differences between lag 2 and the other items in the third interval, and lag 2 items show the greatest positivity in the third interval for both the word and picture groups. Because our third interval is similar to the parietal ERP component, this finding suggests that recollection may play a prominent role in identification of these very recently seen lag 2 items, consistent with previous studies (Dodson \& Schacter, 2002a, 2002b). Recollection of the source, or item-specific, information of seeing the repeated new words earlier on the test may serve as a "recall-to-reject" mechanism, reducing false recognition when the new words repeat after short lag intervals (Rotello, Macmillan, \& Van Tassel, 2000; Rotello \& Heit, 1999; Clark \& Gronlund, 1996). If rejecting a lag 2 item involves recollection of the recently seen word rather than recollection of the study items, then it would be expected that both picture and word groups should show similar brain activity and performance for the lag 2 items. Participants in the picture and word groups do, in fact, show near-identical brain activity (Figure 2) and similar performance (Table 1) for the lag 2 items (see also Results).

The idea that our young subjects used a recall-toreject mechanism to reduce false recognition to lag 2 items is consistent with work by Dywan and colleagues. In their ERP studies using very similar repetition-lag paradigms (with words only), Dywan, Segalowitz, and Arsenault (2002) and Dywan, Segalowitz, and Webster (1998) found that young adults were faster at rejecting lag 6 items compared with novel items, presumably due to a recall-to-reject mechanism. The ERP results of these studies, however, differed somewhat from those of our word group and, in fact, bore more resemblance to those of our picture group in some instances. For example, in the study of Dywan, Segalowitz, and Arsenault, study items were more positive than novel items from 400 to $800 \mathrm{msec}$; such a difference was found in our picture group but not in our word group. This and other differences between our results and theirs may simply reflect the difference in the number of study and test items (100 and 300 vs. 25 and 131) and lags (2 and 48 vs. 6) used. Another more interesting possibility is that, by instructing the subjects to "read each word out loud"-rather than syllable count, as in our paradigmthey may have actually encouraged participants to use the distinctiveness heuristic to distinguish studied versus lag items (in addition to the greater recollection that their encoding task presumably engendered). That is, subjects may have used the rule of thumb, "if I had read this word out loud, I would remember it," as occurred in the study of Dodson and Schacter (2001) when some subjects said aloud target words on study lists compared with others who heard the target words. Thus, the ERP results from 400 to $800 \mathrm{msec}$ in the studies of Dywan, Segalowitz, and Arsenault (2002) and Dywan, Segalowitz, and Webster (1998) may have been attributable to participants relying on recollection to distinguish items types because of the distinctiveness heuristic and the retrieval orientation that it facilitates.

The findings in Figure 3, showing the differences between the word and picture groups for the correct rejection of novel items (reflecting the topography of the difference between the waves in Figure 1), deserve comment. Although the differences in the first interval are mainly midline without a significant anteriorposterior gradient, the word group shows greater positivity in their brain responses to the novel items than the picture group in midline frontal and central regions during the second and third intervals (supported by the near-significant Group $\times$ Electrode interaction in the second interval and subsequent post hoc tests). Because the electrical brain activity of the first interval did not help subjects to distinguish between item types, and there was no difference between groups for the fourth interval, it may be that the fronto-central difference of activity in the second and third intervals represents the neural correlate of the distinctiveness heuristic. Although one cannot draw reliable neuroanatomical inferences regarding the neural generators of ERP data, it is interesting to note that a number of studies have also suggested that the frontal lobes may be important in metacognitive processes including the distinctiveness heuristic. Johnson and colleagues have suggested that right frontal regions, in particular, may support judgments based on qualities which are relatively easily assessed (such as perceptual detail or familiarity), and that left or bilateral frontal regions are needed for more systematic judgments when more careful analysis of the memory is needed (Mitchell, Johnson, Raye, \& Green, 2004; Johnson \& Raye, 1998; Johnson, Kounios, \& Nolde, 1996). ${ }^{3}$ In their review of the neuroimaging literature, Fletcher and Henson (2001) suggested that the anterior frontal cortex (the anterior edge of the inferior frontal gyrus) is important in selecting goals and coordinating other brain regions to achieve those goals, and its activation is commonly seen during the adoption of specific strategies of memory retrieval to assist in goal-directed behavior. Two other reviews suggest that midfrontal brain regions may be particularly important for metacognition (FernandezDuque et al., 2000; Shimamura, 2000). Lastly, Budson, Dodson, Vatner, et al. (2005) found that patients with frontal lobe lesions were unable to use the distinctiveness heuristic to reduce their false recognition.

The present study helps to explain the findings of previous reports investigating the use of the distinctiveness heuristic in different patient populations. Budson, 
Dodson, Daffner, et al. (2005) studied patients with Alzheimer's disease, and Weiss, Dodson, Goff, Schacter, and Heckers (2002) studied patients with schizophrenia. Each of these patient groups was able to use the distinctiveness heuristic to reduce their false recognition to an extent similar to the control groups. However, compared to those who studied words, the patients who studied pictures showed lower levels of true recognition in addition to their reduced false recognition. To understand these findings, we must first note that both patients with Alzheimer's disease and those with schizophrenia are known to show impaired recollection due to medial-temporal lobe dysfunction (Smith \& Knight, 2002; Heckers et al., 1998). As expected, patients in both the picture and word conditions thus show impaired recollection of the studied items. In the present study, we have suggested that the distinctiveness heuristic occurs because participants in picture group use recollection alone to determine if test items were studied-only test items which engender recollection of pictorial information support a positive recognition decision. Because the patients show impaired recollection of this pictorial information, they will most likely reject large numbers of study items that are not recollected at test. Of course, the word group also shows impaired recollection of the study items, but because they do not demand access to recollection of detailed study information to make their recognition decision-relying instead on familiarity and postretrieval processes-they will not reject an item simply because they cannot recollect it. Thus, patients with Alzheimer's disease and schizophrenia in the picture condition show lower levels of both false and true recognition compared with those in the word condition because those in the picture condition rely upon a recollection system which is dysfunctional.

Our investigation of the distinctiveness heuristic found that ERPs to novel items were more negative in the picture versus word encoding condition, consistent with previous work by Herron and Rugg (2003) and Robb and Rugg (2002). These studies, using withinsubjects manipulations, demonstrated that retrieval orientation can be altered by whether words or pictures were the sought-for-modality. The present study has expanded our knowledge of retrieval orientation in several ways. First, we showed that retrieval orientation can be altered using a between-subjects word versus picture encoding manipulation. Second, unlike Herron and Rugg, and Robb and Rugg, who used different encoding tasks in the picture and word conditions in an effort to maximize the differences between the conditions, we used an identical encoding task for the two conditions in our study. This task congruity enabled us to observe changes in retrieval orientation solely related to a change in the study material. Lastly, our study has shown additional ways in which a change in retrieval orientation can impact performance-by facilitating the reduction of false recognition to novel items even when the novel items are repeated at test.

In conclusion, we have shown that the distinctiveness heuristic can be understood as an adoption of a particular retrieval orientation in which the participants in the picture encoding condition depend upon using recollection to make their decisions regarding the old-new status of a test item. By contrast, participants in the more standard word encoding condition require the engagement of additional postretrieval processes to make their test decisions. Because participants in the picture encoding condition were able to use this retrieval orientation to reduce their false recognition, future studies investigating the distinctiveness heuristic and retrieval orientation may be able to provide strategies to enable healthy and memory impaired individuals to reduce false memories and thereby improve their lives.

\section{METHODS \\ Participants}

Thirty-one right-handed, native English-speaking participants (15 women; mean age 21.5 years, range 2027 years; mean years of education 15.0, range 14-18) were recruited from Harvard University, Cambridge, MA, by e-mail, fliers, and word of mouth. All participants were screened for serious medical conditions and were healthy. Participants were paid US $\$ 25 / \mathrm{hr}$. The study was approved by the human subjects committees of Harvard University and Brigham and Women's Hospital, Boston, MA. Written informed consent was obtained from all participants. All participants were tested during one sitting at Brigham and Women's Hospital. Data were reported and analyzed from 24 participants (10 women). [Seven participants' data were rejected because of less than 16 artifact-free trials per condition ( 4 participants), behavioral performance outside of 3 standard deviations compared to the other participants (2 participants), or they did not follow task instructions (1 participant).]

\section{Paradigm Materials and Design}

The stimuli consisted of 200 Snodgrass and Vanderwart (1980) pictures and their corresponding labels. The stimuli were divided into four lists of 50 stimuli each. Each of the lists were compiled so that they had similar mean ratings for picture familiarity (average 3.52 out of 5 ), picture complexity (average 2.73 out of 5), and word frequency (average 32.74). Participants were randomly assigned to a counterbalanced arrangement of the lists (A, B, C, or D). Although all participants heard the auditory label at study, half of the participants also saw the corresponding picture, and the other half saw the word visually presented. All participants were presented with both visual and auditory words at test. One hundred items (two lists) were presented at study and 
served as the study item type at test. The other 100 items (the other two lists) were new at test and served as the novel items. Fifty of those novel items (one of the lists used as novel) were presented again at test after an intervening lag of two items from their initial presentation (lag 2 items); the other 50 of the novel items (the other list that was used as novel) were presented again at test after an intervening lag of 48 items from their initial presentation (lag 48 items). Thus, 300 items were presented at test. Visual word items were presented in white against a black background in Arial font size 40. Snodgrass and Vanderwart pictures were black on a white background. Stimuli were presented to the participants by the StimMixed program run from an Intel Pentium computer and were viewed on a 16-in. color monitor with $640 \times 480$ screen resolution. The stimuli were centered and encompassed the entire monitor screen. The auditory words were presented through headphones at the same time the visual stimuli were presented.

\section{ERP Materials and Method}

ERPs were recorded from participants through the use of an electrode cap (Electro-Cap International, Eaton, $\mathrm{OH})$, which held the 29 tin electrodes to the scalp. The electrode sites consisted of 3 midline (Fz, Cz, Pz) and 26 lateral sites (arranged in 4 coronal rows from anterior to posterior sites (a: F7/8, AF7/8, FP1/2; b: T3/4, FC5/6, F3/4, FC1/2; c: CP5/6, C3/4, CP1/2; d: T5/6, P3/4, $\mathrm{O} 1 / 2)$. These sites were all referenced to the left mastoid and the impedance between each recording site and the reference site was reduced to less than $15 \mathrm{k} \Omega$. Three tin biopotential electrodes (referenced to the left mastoid) were placed to monitor eye movements: one beneath the left eye (LE) (to check for eye blinks and vertical eye movements) and the others at the outer canthi of the participants' right and left eyes (HE) (to check for lateral eye movements). There was an electrode (A2) placed over the left mastoid in order to serve as a reference for the 32 tin electrodes as well as a final electrode (A1) placed over the right mastoid (referenced to the left) to monitor asymmetric mastoid activity; none was found. To increase conductance, all electrodes were filled with Quik-Gel Conductive Gel (Neurosoft, El Paso, TX). The electroencephalogram (EEG) was recorded on an SA Instrumentation bioelectric amplifier (Encinitas, CA; model B\&W $32 \mathrm{BA}$ ) and continuously digitized $(200 \mathrm{~Hz})$ by a PC-compatible microcomputer that yielded $2560 \mathrm{msec}$ of data from each electrode site, beginning $100 \mathrm{msec}$ before stimulus onset. Participants were seated in a dimly lit, sound-attenuated room, $5 \mathrm{ft}$ in front of the computer screen. Participants responded "yes" or "no" to items at study and test using a joystick.

For the study phase, all participants were instructed to engage in a syllable counting task by answering "yes" or "no" to the question, "Does the item consist of more than two syllables?" when cued by a plus sign. Participants were not informed that they would be tested later for their memory of these study items. At test, participants were instructed to perform a "yes/no" task in which they were instructed to answer the question "Was this item present in the syllable counting task?" Participants who had studied pictures were informed that they would see visual words corresponding to the pictures, whereas participants who studied visual words were instructed that they would see visual words again. Participants were instructed that there would be novel words on the test as well, and they were specifically told that all the novel words would be repeated.

Both study and test items were presented for $1500 \mathrm{msec}$, followed by $500 \mathrm{msec}$ of blank screen, followed by the plus sign that cued participants to respond. The plus sign remained until the participants responded and was then followed by 500 msec of blank screen, after which a focus point (asterisk) remained on the screen for 1500 msec. After another 500 msec of blank screen, the next item was presented. Participants were instructed to try not to blink or move their eyes while the study and test items were on the screen. There were several pauses during the experiment to allow data to be transferred to the hard drive and to allow the participant to blink as needed and rest their eyes.

\section{Data Analysis}

Continuous raw EEG data were recorded. EEG epochs for the two different groups (word and picture) and four different item types (correct responses to study, novel, lag 2, and lag 48 items) were averaged separately. Trials with either excessive eye movements $(>50 \mu \mathrm{V}$ peak-topeak amplitude) in either of the outer canthi channels (left or right) or amplifier blocking were excluded from data analysis. For trials with excessive eye blinks $(>50 \mu \mathrm{V}$ peak-to-peak amplitude in the channel below the left eye), a blink correction program (Dale, 1994) was employed that computed the impact of the blink on the waveforms in each channel. The ERP data were analyzed by dividing the wave into four frequently studied components of a recognition memory test ERP wave, the P200, the N400, the parietal component, and the late frontal component (e.g., Curran et al., 2001). The particular temporal intervals used for defining P200, N400, parietal, and late frontal effects were determined by visual inspection after reviewing the individual ERP plots for all subjects. The first interval (P200) was defined as 150 to $300 \mathrm{msec}$ after stimulus onset, the second interval (N400) from 300 to $550 \mathrm{msec}$, the third interval (parietal component) from 550 to $1000 \mathrm{msec}$, and the fourth interval (late frontal component) from 1000 to $2000 \mathrm{msec}$. Mean amplitudes were calculated for each interval and used in the ERP analyses. Amplitudes were measured with respect to the average of the 
100-msec prestimulus baseline. Data were analyzed using repeated-measures ANOVAs using SPSS 10.0.5 (SPSS, Chicago, IL). The Greenhouse-Geisser procedure was used for all ANOVAs with greater than one numerator degree of freedom.

\section{Acknowledgments}

This research was supported by National Institute on Aging P30 AG13846, National Institute of Mental Health K23 MH01870, and the Brigham and Women's Hospital Faculty Award in Translational Neurosciences. We thank Alison Sullivan, Rachel Goldmann, and Hyemi Chong for help in running subjects and preparing data. We also thank Dave Wolk and Dave Gallo for their helpful comments on the manuscript.

Reprint requests should be sent to Andrew E. Budson, Geriatric Research Education Clinical Center, Edith Nourse Rogers Memorial Veterans Hospital, Bldg. 62, Rm. B30, 200 Springs Road, Bedford, MA 01730, USA, or via e-mail: abudson@bu.edu.

\section{Notes}

1. Note that the ERP waves for the lag 2 items were almost exactly the same for the word and picture groups (Figure 2), suggesting that the differences between the groups observed for the study and novel items cannot be due to subject variability or other nonspecific factors.

2. Note that participants in both word and picture groups also found some test items more familiar than others, reflected by differences in the N400 component.

3. Note that Johnson and colleagues refer to judgments which are easily assessed as "heuristic" judgments. This heuristic facilitates "old" and "new" responses to items which may be easily judged based upon their familiarity, perceptual details, and so forth. This kind of a heuristic is somewhat different from the distinctiveness heuristic which allows participants to easily respond "new" to items for which they do not recollect the picture at study.

\section{REFERENCES}

Allan, K., Wilding, E. L., \& Rugg, M. D. (1998).

Electrophysiological evidence for dissociable processes contributing to recollection. Acta Psychologica, 98, 231-252.

Budson, A. E., Dodson, C. S., Daffner, K. R., \& Schacter, D. L. (2005). Metacognition and false recognition in Alzheimer's disease: Further exploration of the distinctiveness heuristic. Neuropsychology, 19, 253-258.

Budson, A. E., Dodson, C. S., Vatner, J. M., Daffner, K. R., Black, P. M., \& Schacter, D. L. (2005). Metacognition and false recognition in patients with frontal lobe lesions: The distinctiveness heuristic. Neuropsvchologia 43, 860-871.

Budson, A. E., Daffner, K. R., Desikan, R., \& Schacter, D. L. (2000). When false recognition is unopposed by true recognition: Gist-based memory distortion in Alzheimer's disease. Neuropsychology, 14, 277-287.

Budson, A. E., Sitarski, J., Daffner, K. R., \& Schacter, D. L. (2002). False recognition of pictures versus words in Alzheimer's disease: The distinctiveness heuristic. Neuropsychology, 16, 163-173.
Chaiken, S., Lieberman, A., \& Eagly, A. H. (1989). Heuristic and systematic information processing within and beyond the persuasion context. In J. S. Uleman \& J. A. Bargh (Eds.), Unintended thought (pp. 212-252). New York: Guilford Press.

Clark, S. E., \& Gronlund, S. D. (1996). Global matching models of memory: How the models match the data. Psychonomic Bulletin \& Review, 3, 37-60.

Curran, T. (2000). Brain potentials of recollection and familiarity. Memory and Cognition, 28, 923-938.

Curran, T., \& Cleary, A. M. (2003). Using ERPs to dissociate recollection from familiarity in picture recognition. Cognitive Brain Research, 15, 191-205.

Curran, T., Schacter, D. L., Johnson, M. K., \& Spinks, R. A. (2001). Brain potentials reflect behavioral differences in true and false recognition. Journal of Cognitive Neuroscience, 13, 201-216.

Dale, A. M. (1994). Source localization and spatial discriminant analysis of event-related potentials: Linear approaches (brain cortical surface). Dissertation Abstracts International, 55-07B, 2559.

Dodson, C. S., Koutstaal, W., \& Schacter, D. L. (2000). Escape from illusion: Reducing false memories. Trends in Cognitive Sciences, 4, 391-397.

Dodson, C. S., \& Schacter, D. L. (2001). 'If I had said it I would have remembered it': Reducing false memories with a distinctiveness heuristic. Psychonomic Bulletin $\&$ Review, 8, $155-161$.

Dodson, C. S., \& Schacter, D. L. (2002a). When false recognition meets metacognition: The distinctiveness heuristic. Journal of Memory and Language, 46, 782-803.

Dodson, C. S., \& Schacter, D. L. (2002b). Aging and strategic retrieval processes: Reducing false memories with a distinctiveness heuristic. Psychology and Aging, 17, 405-415.

Duzel, E., Yonelinas, A. P., Mangun, G. R., Heinze, H. J., \& Tulving, E. (1997). Event-related brain potential correlates of two states of conscious awareness in memory. Proceedings of the National Academv of Sciences, U.S.A., 94, 5973-5978

Dywan, J., Segalowitz, S., \& Arsenault, A. (2002). Electrophysiological response during source memory decisions in older and younger adults. Brain and Cognition. 49, 322-340.

Dywan, J., Segalowitz, S. J., \& Webster, L. (1998). Source monitoring: ERP evidence for greater reactivity to nontarget information in older adults. Brain and Cognition, 36, $390-430$

Fernandez-Duque, D., Baird, J. A., \& Posner, M. I. (2000). Executive attention and metacognitive regulation. Conscious and Cognition, 9, 288-307.

Fletcher, P. C., \& Henson, R. N. A. (2001). Frontal lobes and human memory: Insights from functional neuroimaging. Brain, 124, 849-881.

Gallo, D. A., Weiss, J. A., \& Schacter, D. L. (2004). Monitoring false recognition with criterial recollection tests: Distinctiveness heuristic versus criterion shifts. Dournal of Memorv \& Language, 51, 473-493.

Goldmann, R. E., Sullivan, A. L., Droller, D. B., Rugg, M. D., Curran, T., Holcomb, P. J., Schacter, D. L., Daffner, K. R., \& Budson, A. E. (2003). Late frontal brain potentials distinguish true and false recognition. NeuroReport. 14, 1717-1720.

Heckers, S., Rauch, S. L., Goff, D., Savage, C. R., Schacter, D. L., Fischman, A. J., \& Alpert, N. M. (1998). Impaired recruitment of the hippocampus during conscious recollection in schizophrenia. Nature Neuroscience, 1, 318-323.

Henson, R. N., Rylands, A., Ross, E., Vuilleumeir, P., \& Rugg, M. D. (2004). The effect of repetition lag on 
electrophysiological and haemodynamic correlates of visual object priming. Neuroimage, 21, 1674-1689.

Herron, J. E., \& Rugg, M. D. (2003). Retrieval orientation and the control of recollection. Journal of Cognitive Neuroscience, 15, 843-854.

Israel, L., \& Schacter, D. L. (1997). Pictorial encoding reduces false recognition of semantic associates. Psychonomic Bulletin \& Review, 4, 577-581.

Jennings, J. M., \& Jacoby, L. L. (1997). An opposition procedure for detecting age-related deficits in recollecting: Telling effects of repetition. Psychology and Aging, 12, 352-361.

Johnson, M. K., Hashtroudi, S., \& Lindsay, D. S. (1993). Source monitoring. Psvchological Bulletin, 114, 126-135.

Johnson, M. K., Kounios, J., \& Nolde, S. F. (1996).

Electrophysiological brain activity and memory source monitoring. NeuroReport, 7, 2929-2932.

Johnson, M. K., Nolde, S. F., Mather, M., Kounios, J., Schacter, D. L., \& Curran, T. (1997). The similarity of brain activity associated with true and false recognition memory depends on test format. Psvchological Science, 8, 250-257.

Johnson, M. K., \& Raye, C. L. (1998). False memories and confabulation. Trends in Cognitive Sciences, 2, 137-145.

Kahneman, D., Slovic, P., \& Tversky, A. (1982). Judgement under uncertainty: Heuristics and biases. New York: Cambridge University Press.

Kensinger, E. A., \& Schacter, D. L. (1999). When true memories suppress false memories: Effects of aging. Cognitive Neuropsychology, 16, 399-415.

McDermott, K. B. (1996). The persistence of false memories in list recall. Journal of Memorv and Language, 35, 212-230.

Mitchell, K. J., Johnson, M. K., Raye, C. L., \& Greene, E. J. (2004). Prefrontal cortex activity associated with source monitoring in a working memory task. Journal of Cognitive Neuroscience, 16, 921-934.

Nessler, D., Mecklinger, A., \& Penney, T. B. (2001). Event related brain potentials and illusory memories: Effects of differential encoding. Cognitive Brain Research, 10, 283-301.

Ranganath, C., \& Paller, K. A. (2000). Neural correlates of memory retrieval and evaluation. Cognitive Brain Research. 9, 209-222.

Robb, W. G., \& Rugg, M. D. (2002). Electrophysiological dissociation of retrieval orientation and retrieval effort. Psychonomic Bulletin E Review, 9, 583-589.

Rotello, C. M., \& Heit, E. (1999). Two-process models of recognition memory: Evidence for recall-to-reject? Iournal of Memory and Lanquage, 40, 432-453.

Rotello, C. M., Macmillan, N. A., \& Van Tassel, G. (2000).
Recall-to-reject in recognition: Evidence from ROC curves. Journal of Memorv and Language, 43, 67-88.

Rugg, M. D., \& Allan, K. (2000). Memory retrieval: An electrophysiological perspective. In M. S. Gazzaniga (Ed.), The new cognitive neurosciences (pp. 805-816). Cambridge: MIT Press.

Rugg, M. D., \& Wilding, E. L. (2000). Retrieval processing and episodic memory. Trends in Cognitive Sciences, 4, 108-115.

Schacter, D. L. (1996). Searching for memory: The brain, the mind, and the past. New York, NY: Basic Books.

Schacter, D. L., Israel, L., \& Racine, C. (1999). Suppressing false recognition in younger and older adults: The distinctiveness heuristic. Journal of Memorv and Language, 40, 1-24.

Schacter, D. L., Verfaellie, M., Anes, M. D., \& Racine, C. (1998). When true recognition suppresses false recognition: Evidence from amnesic patients. Journal of Cognitive Neuroscience, 10, 668-679.

Schacter, D. L., \& Wiseman, A. L. (in press). Reducing memory errors: The distinctiveness heuristic. In R. R. Hunt \& J. Worthen (Eds.), Distinctiveness and memory. New York: Oxford University Press.

Shimamura, A. P. (2000). Toward a cognitive neuroscience of metacognition. Conscious and Cognition, 9, 313-323.

Smith, J. A., \& Knight, R. G. (2002). Memory processing in Alzheimer's disease. Neuropsvchologia, 40, 666-682.

Snodgrass, J. G., \& Corwin, J. (1988). Pragmatics of measuring recognition memory: Applications to dementia and amnesia. Journal of Experimental Psychology: General 117, 34-50.

Snodgrass, J. G., \& Vanderwart, M. (1980). A standardized set of 260 pictures: Norms for name agreement, image agreement, familiarity, and visual complexity. Iournal of Experimental Psychology: Human Learning and Memory. 6, 174-215.

Strack, F., \& Bless, H. (1994). Memory for nonoccurrences: Metacognitive and presuppositional strategies. Lournal of Memory and Language, 33, 203-217.

Underwood, B. J., \& Freund, J. S. (1970). Testing effects in the recognition of words. Journal of Verbal Learning and Verbal Behavior, 9, 117-125.

Weiss, A. P., Dodson, C. S., Goff, D. C., Schacter, D. L., \& Heckers, S. (2002). Intact suppression of increased false recognition in schizophrenia. American Journal of Psvchiatry, 159, 1506-1513.

Wilding, E. L., \& Rugg, M. D. (1996). An event-related potential study of recognition memory with and without retrieval of source. Brain, 119, 889-905.

Yovel, G., \& Paller, K. A. (2004). The neural basis of the butcher-on-the-bus phenomenon: When a face seems familiar but is not remembered. Neuroimage, 21, 789-800. 


\section{This article has been cited by:}

1. David A. Gallo, Ian M. McDonough, Jason Scimeca. Dissociating Source Memory Decisions in the Prefrontal Cortex: fMRI of Diagnostic and Disqualifying MonitoringDissociating Source Memory Decisions in the Prefrontal Cortex: fMRI of Diagnostic and Disqualifying Monitoring. Journal of Cognitive Neuroscience, ahead of print1-15. [Abstract] [PDF] [PDF Plus]

2. Taylor M. Joerger, Jennifer A. Mangels. 2008. Neural correlates of false memory disqualification by true recollection of feedback. NeuroReport 19:17, 1695-1698. [CrossRef]

3. Allen Azizian, Todd D. Watson, Muhammad A. Parvaz, Nancy K. Squires. 2006. Time Course of Processes Underlying Picture and Word Evaluation: An Event-Related Potential Approach. Brain Topograpby 18:3, 213-222. [CrossRef]

4. David A. Gallo, Elizabeth A. Kensinger, Daniel L. Schacter . 2006. Prefrontal Activity and Diagnostic Monitoring of Memory Retrieval: $\mathrm{fMRI}$ of the Criterial Recollection TaskPrefrontal Activity and Diagnostic Monitoring of Memory Retrieval: $\mathrm{fMRI}$ of the Criterial Recollection Task. Journal of Cognitive Neuroscience 18:1, 135-148. [Abstract] [PDF] [PDF Plus] 